\title{
Effects of Overpressure Processing on Porosity in Ag-Sheathed Bi-2212 Multifilamentary Tapes with Various Geometries
}

\author{
J.L. Reeves, E.E. Hellstrom \\ Materials Science Program and Applied Superconductivity Center, UW-Madison, Madison, WI \\ V. Irizarry \\ University of Puerto Rico-Mayaguez \\ B. Lehndorff \\ University Of Wuppertal, Wuppertal, Germany
}

\begin{abstract}
In long lengths of $\mathrm{Bi}-2212$ tapes and wires, gases such as $\mathrm{CO}_{2}$ and $\mathrm{H}_{2} \mathrm{O}$ can cause bubbling of the $\mathrm{Ag}$-sheath and porosity in the superconducting core. Applying a pre-processing step, which consists of vacuum annealing and annealing at $835^{\circ} \mathrm{C}$ in $100 \% \mathrm{O}_{2}(\mathrm{VA}+835)$, eliminates $\mathrm{H}_{2} \mathrm{O}$ and reduces $\mathrm{CO}_{2}$ that evolves during heating. To also counteract porosity, an overpressure heat treatment was utilized. Air was compressed to $5 \mathrm{~atm}$ total pressure $\left(\mathrm{P}_{\text {total }}\right)$ while keeping $\mathrm{pO}_{2}$ fixed at $1 \mathrm{~atm}$. Thickness variations were measured for a number of variables: with and without $V A+835 ; P_{\text {total }}=1$ or $5 \mathrm{~atm}$; and sample geometry such as round wires and rectangular tapes with different silver wall thickness. Light micrographs and SEM images show thin-walled monocore and multifilamentary tapes bubble unless they are pre-processed. The size and shape of pores in thick and thin multifilaments changes with overpressure processing. Microstructures with smaller and more uniformly distributed pores correlate with higher critical current values.
\end{abstract}

\section{INTRODUCTION}

Porosity remains a problem in processing long lengths of Bi-2212 tapes and wires. While short lengths have maximum critical current densities of $>10^{5} \mathrm{~A} / \mathrm{cm}^{2}$, that value is difficult to achieve in long lengths. Since porosity (due to both the initial packing density and gases formed in the initial stages of processing) inhibits $J_{c}$ in long lengths of $\mathrm{Bi}-2212$, understanding how to prevent porosity is an important goal of current research.

Studies done on the powder density during the OPIT process show that core density increases with increasing deformation. The core density reaches a maximum of $75 \%$, and levels off with increasing deformation [1]. That leaves $25 \%$ porosity in the green wire or tape. During heat treatment, the silver can creep [2] which allows the silver sheath to collapse if it is thin enough. Applying an overpressure during processing may help the silver sheath collapse and densify the core [3]. In this experiment the total pressure was varied from $1 \mathrm{~atm}$ to $5 \mathrm{~atm}$ to see how samples

Manuscript received September 15, 1998. This work was supported by the BMBF under contract number 13 N6634/2 with Cryoelectra GmbH. Partial support for electron microscopy facilities is provided by the NSF MRSEC on Nanostructured Materials at the University of Wisconsin-Madison under contract DMR-9632427. with different geometries and varying $\mathrm{Ag}$-sheath thicknesses were affected. Another source of porosity is trapped gases such as water and $\mathrm{CO}_{2}$, or $\mathrm{O}_{2}$ that evolves too quickly when heating through the melting point of $\mathrm{Bi}-2212$. All of these gases can cause bubbling of the silver sheath and porosity in the core. It is possible, however, to reduce or eliminate the deleterious effects of these gases by the proper heattreatment. FTIR spectra in Fig. 1 show that water is removed by heating to $700^{\circ} \mathrm{C}$ in partial vacuum and holding at $700^{\circ} \mathrm{C}$ for 1 day. FTIR results also show that most of the $\mathrm{CO}_{2}$ is removed by heating from $700^{\circ}$ to $835^{\circ} \mathrm{C}$ and holding at $835^{\circ} \mathrm{C}$ for 2 days in $100 \% \mathrm{O}_{2}$. Finally, by heating slowly $\left(60^{\circ} \mathrm{C} / \mathrm{hr}\right)$ through the melting point of $\mathrm{Bi}-2212$, bubbling due to fast $\mathrm{O}_{2}$ evolution can be prevented.

\section{EXPERIMENTAL PROCEDURE}

We studied how conductor geometry, total pressure, and preprocessing affected porosity. We used the following samples: $165 \mu \mathrm{m}$ thick monocore tape, multifilamentary tape of two different thickness from Cryoelectra GmbH (360 $\mu \mathrm{m}$ and $775 \mu \mathrm{m})$, and multifilamentary wire from IGC $(810 \mu \mathrm{m}$ in diameter, 290 filaments). The $\mathrm{pO}_{2}$ was fixed at 1 atm for two different total pressures of 1 and $5 \mathrm{~atm}$. Four to six $\mathrm{cm}$ long pieces of each of the four kinds of samples were preprocessed with the vacuum annealing plus $835^{\circ} \mathrm{C}(\mathrm{VA}+835)$ step shown on the left in Fig. 2. Two pieces of each sample, one green and one with the VA+835 step, were incompletely processed using the heat treatment shown on the right in Fig. 2.

We measured the thickness or diameter of the green and VA+835 step tapes and wires before and after this heattreatment since thickness is an indirect measure of the porosity in the superconductor. A denser, less porous, core will be thinner than a porous one. The samples were also mounted in epoxy and polished for imaging. Microstructures were analyzed using the LEO 982 scanning electron microscope and a light microscope.

\section{RESULTS AND DISCUSSION}

Thickness was measured on the sample before and after heat treatment. The percent change in thickness was calculated by subtracting the initial thickness from the final thickness and dividing by the initial thickness. Table I lists the 
$\mathrm{H}_{2} \mathrm{O}$ Evolution

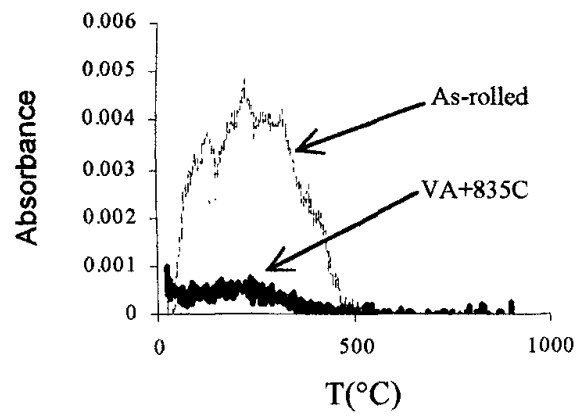

$\mathrm{CO}_{2}$ Evolution

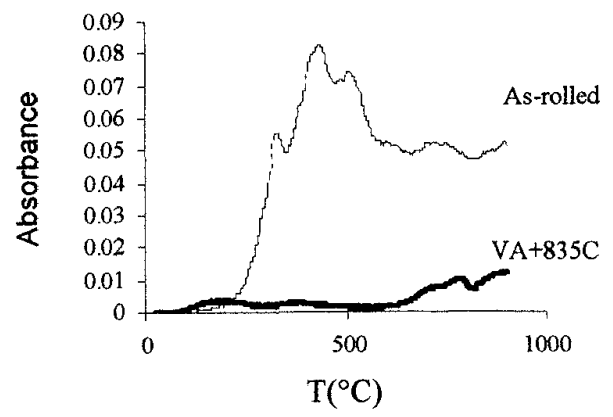

Fig. 1. Fourier Transform Infrared spectra showing the amount of water (left) and $\mathrm{CO}_{2}$ (right) evolving from samples processed either with or without the $\mathrm{VA}+835$ step.
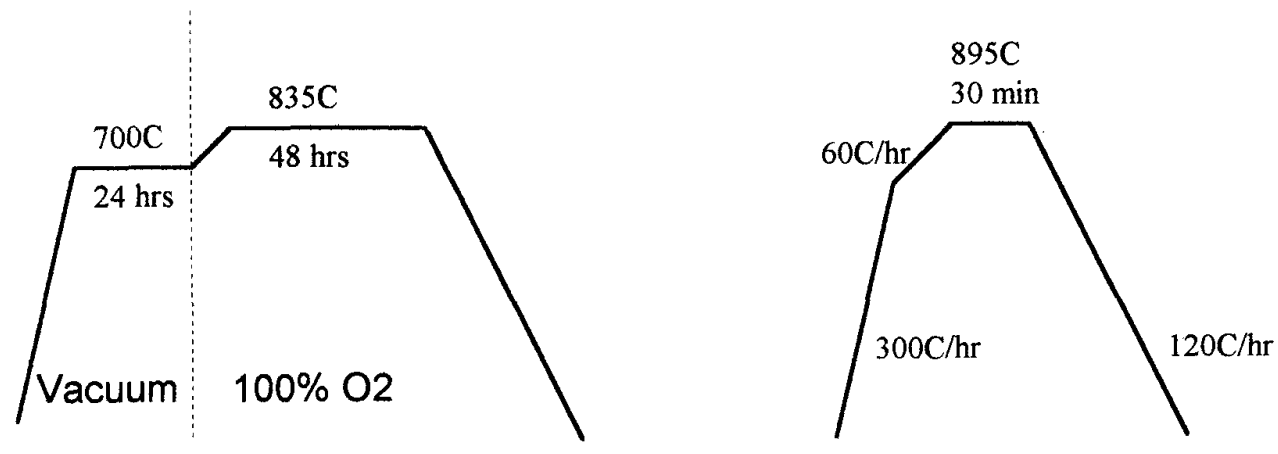

Fig. 2. Vacuum anneal and anneal at $835^{\circ} \mathrm{C}$ (left) and heat treatment of samples (right).
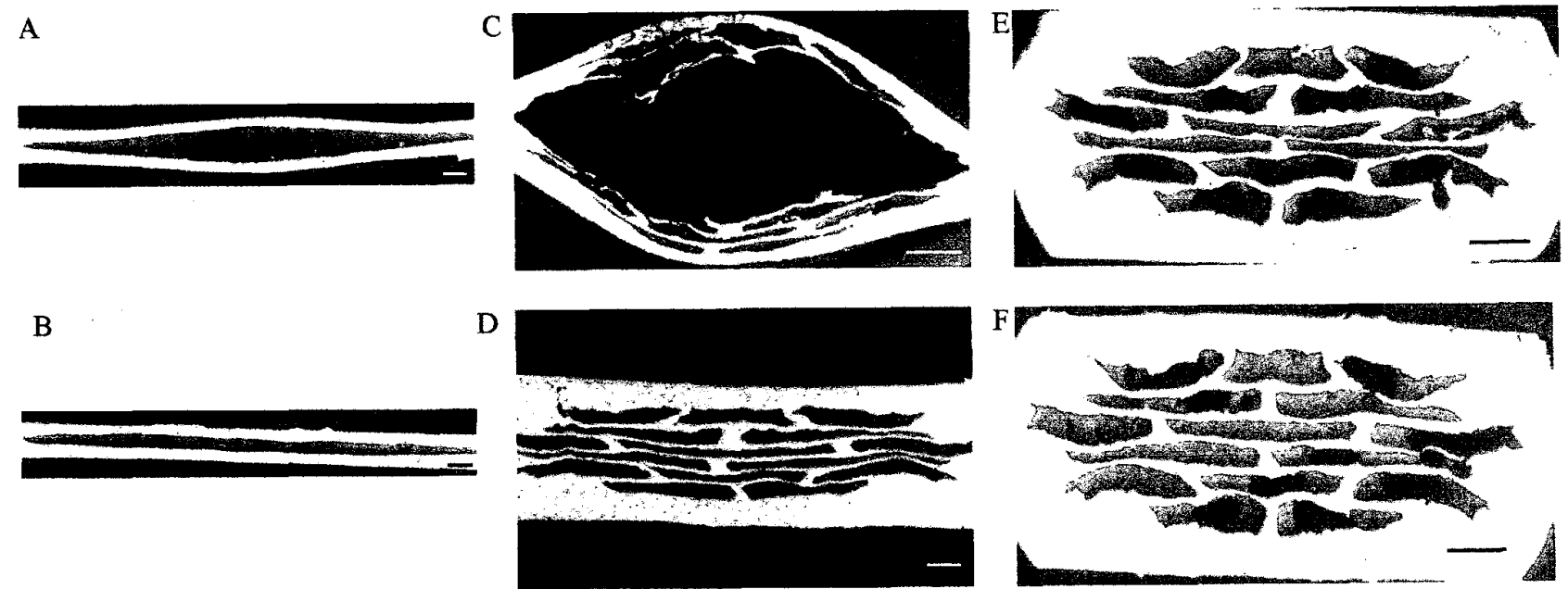

Fig. 3. Light micrographs of transverse cross-sections of monocore tape (a, b), thin multifilament (c, d), and thick multifilament (e, $f$ ) showing bubbling and porosity. The top row shows samples that were not pretreated with the VA+835 step before processing at 1 atm. The samples in the bottom row were vacuum annealed and annealed at $835^{\circ} \mathrm{C}$. The round, dark features are pores. The length marker in the bottom right corner of each picture represents $200 \mu \mathrm{m}$. 
percent change in thickness for samples of different geometry processed at either $1 \mathrm{~atm}$ or $5 \mathrm{~atm}$ total pressure. The samples were not subjected to a VA+835 preprocessing step. Both the monocore tape and the thin multifilament tape bubbled when processed at $1 \mathrm{~atm}$, while the thick tape and round wire did not bubble. Even without VA+835, applying an overpressure stopped the Ag-sheath from bubbling and reduced the thickness of the monocore tape and thin multifilament tape. Although overpressure did not collapse the thick multifilament or the round wire, the swelling was comparable in the thick multifilament and reduced in the round wire.

Table II shows the effect of increasing pressure on thickness when the samples were subjected to a VA+835 preprocessing step. With VA+835, none of the samples bubbled when processed at 1 atm. The decrease in thickness of the monocore tape, thick multifilament tape, and round multifilament wires was larger at $5 \mathrm{~atm}$ than at $1 \mathrm{~atm}$. This trend was to be expected also for the thin multifilament tape, but the $5 \mathrm{~atm}$ data point seems suspect.

Light microscope images of transverse cross-sections of samples after heat treatment at 1 atm both with and without a VA+835 step are shown in Fig. 3. The severe deformation in the monocore tape and thin multifilament tape is a result of gas evolution during heating. Fig. 3 also shows a large amount of porosity in the core of the thick multifilament tape due to either the initial packing porosity or gas evolution. Samples with thin silver walls (Fig. 3a, Fig. 3c) that were not preprocessed with the VA+835 step could not withstand the pressure due to evolving gases. Removing water and $\mathrm{CO}_{2}$ during the VA+835 step prevented the Ag-sheath from bubbling (Fig. 3b, 3d) when processed at latm. The thick multifilamentary tape (Fig. 3e) has thick enough silver to withstand the evolving gas pressure. However, even though water and $\mathrm{CO}_{2}$ were removed by VA+835, porosity remains in the core of the thick multifilament (Fig. $3 \mathrm{f}$ ) because the silver walls could not collapse under the external pressure of only 1 atm.

Fig. 4 shows SEM images of multifilamentary tapes after processing at 5atm. Multiple transverse cross-sections were photographed, and image processing shows that porosity is about $5-6 \%$ of the total tape area in both images. However, the pore morphology is very different. In the thick multifilament the pores are large, approximately $100 \mu \mathrm{m}$ in diameter which is an appreciable fraction of the total crosssectional area of an individual filament. More than half of the filaments contain these large pores. In contrast, only one large pore is seen in this representative area of the thin multifilament. The other filaments contain many small pores. This difference in pore morphology correlates with the difference in critical current values. Thick multifilpments processed at 1 atm total pressure with VA+835 had an average $J_{c}$ of $47 \mathrm{kA} / \mathrm{cm}^{2}$. In comparison, the thick multifilament processed at 5 atm with VA+835 had an average $\mathrm{J}_{\mathrm{c}} 65 \mathrm{kA} / \mathrm{cm}^{2}$ while the average $\mathrm{J}_{\mathrm{c}}$ of the thin multifilament was $82 \mathrm{kA} / \mathrm{cm}^{2}$. Therefore, a combination of removing gases during

\section{TABLE I}

Effect of increasing pressure on thickness of samples with diffenent geometries without VA+835. Positive numbers mean the tape thickness or wire diameter increased after processing; negative numbers mean the thickness/diameter decreased after processing

\begin{tabular}{lll}
\hline Geometry & Ptotal =1 atm & Ptotal = 5 astina \\
\hline Monocore tape & $109 \%$ & $-3.0 \%$ \\
Thin multiflament tape & $281 \%$ & $-3.6 \%$ \\
Thick multifilament tape & $0.4 \%$ & $0.9 \%$ \\
Round multiflament wire & $2.4 \%$ & $0.9 \%$ \\
\hline
\end{tabular}

TABLE II

Effect of increasing pressure on thickness of samples with different geometries with VA+835. Positive numbers mean the thickness/diameter increased after processing; negative numbers mean the thickness/diameter decreased after processing.

\begin{tabular}{lcc}
\hline Geometry & Ptotal = 1 atm & Ptotal = 5 atm \\
\hline Monocore tape & $-3.0 \%$ & $-4.8 \%$ \\
Thin multhilament tape & $-4.2 \%$ & $0.3 \%$ \\
Thick multifilament tape & $0 \%$ & $-0.8 \%$ \\
Round mulifilament wire (84) & $0.2 \%$ & $-0.4 \%$ \\
\hline
\end{tabular}
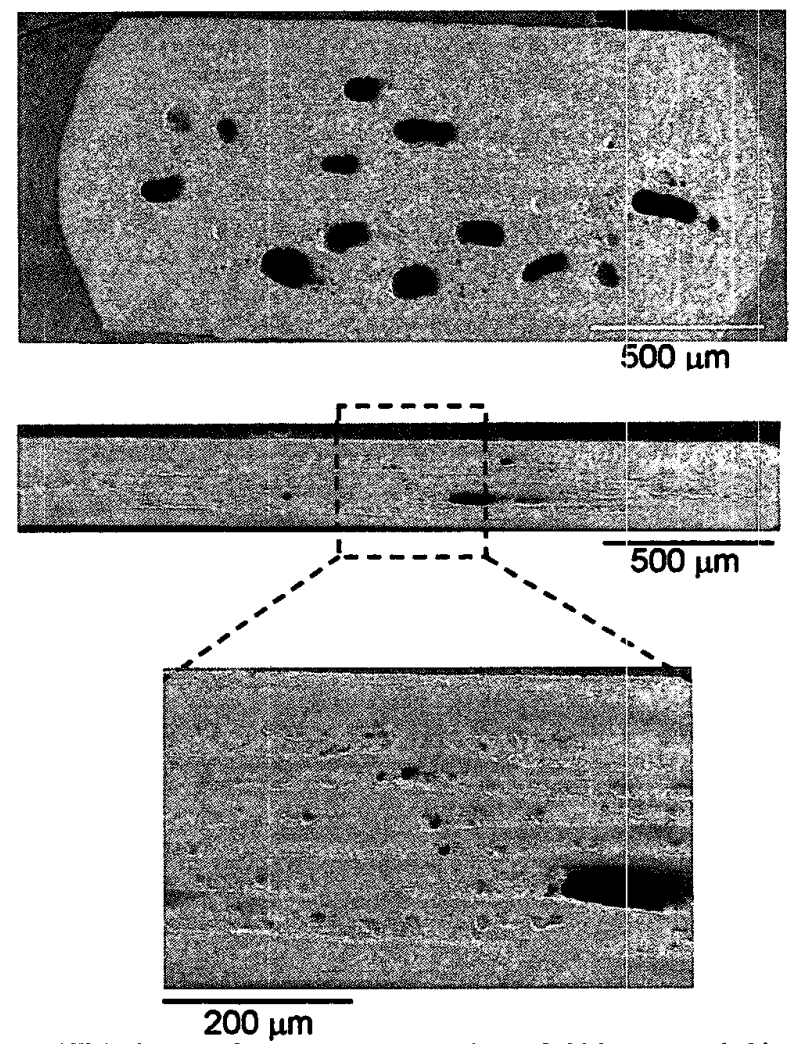

Fig. 4. SEM pictures of transverse cross-sections of thick (top) and thin (below) multifilamentary wires after processing at $5 \mathrm{~atm}$. Pore morphology is very different in the two samples. 
VA +835 and applying a total pressure of 5 atm results in a better pore morphology that correlates to higher $\mathrm{J}_{\mathrm{c}}$.

\section{SUMMARY}

Overpressure processing is effective at eliminating bubbling and reducing porosity in monocore and thin multifilamentary tapes. In addition, using a combination of vacuum annealing at $700^{\circ} \mathrm{C}$ and holding for two days at $835^{\circ} \mathrm{C}$ in $100 \% \mathrm{O}_{2}$ is effective in reducing the amount of water and $\mathrm{CO}_{2}$ in the core which can cause bubbling of the silver sheath. This preprocessing step, in conjunction with overpressure processing, reduced porosity in the superconducting core and increased $\mathrm{J}_{\mathrm{c}}$.

\section{ACKNOWLEDGMENTS}

We would like to thank $M$. Hortig and $H$. Piel of Cryoelectra $\mathrm{GmbH}$ and Lesh Motowidlo of IGC for supplying tape and wire samples for this study.

\section{REFERENCES}

[1] M. Karuna, J. A. Parrell and D. C. Larbalestier, "Study of powder density, Ag: superconductor ratio, and microhardness of BSCCO-2212 Agsheathed wires and tapes during wire drawing and rolling," IEEE Trans. on Appl. Supercond., vol. 5, no. 2, pp.1279-1282, June 1995.

[2] K. C. Goretta, W. E. Delaney, J. L. Routbort, J. Wolfenstine, W. Zhang and E. E. Hellstrom, "Creep of silver at $900^{\circ} \mathrm{C}$," Supercond. Sci. and Tech., vol. 9, pp.422-426, 1996.

[3] J. Reeves, M. Polak, W. Zhang, E. Hellstrom, S. Babcock, and D. Larbalestier, "Overpressure processing of Ag-sheathed Bi-2212 tapes," IEEE Trans. on Appl. Stupercond., vol. 7, no. 2, pp. 1541-1543, June 1997. 